\title{
Covid, el miedo y el estado de emergencia
}

Covid, fear and the state of emergency

\author{
Luciano Vernetti ${ }^{1}$ \\ Universidad de Buenos Aires - Argentina
}

Revista Derechos en Acción ISSN 2525-1678/ e-ISSN 2525-1686

Año 5/Nº 15, Otoño 2020 (21 marzo a 21 junio), 374-400

DOI: https://doi.org/10.24215/25251678e405

... la "sana, vigorosa, amplia y decidida vida parlamentaria es un paradigmático escenario para el desenvolvimiento de la democracia constitucional".

Raúl Gustavo Ferreyra²

\section{Reflexiones preliminares}

La llegada del Corona virus (COVID-19) a China y luego al resto de los países, su meteórica expansión, y el gran número de fallecimiento de adultos mayores especialmente en algunos países, ha traído consigo la peor de las enfermedades "el miedo".

Agamben recientemente ha dicho:

"El miedo es un mal consejero, pero trae a colación muchas cosas que fingíamos no ver. Lo primero que muestra claramente la ola de pánico que paralizó al país es que nuestra sociedad ya no cree en nada excepto en la vida desnuda. Está claro que los italianos están dispuestos a sacrificar prácticamente todo, condiciones de vida normales, relaciones

\footnotetext{
1 Abogado, especialista en Tributación por la Universidad de Buenos Aires, Argentina. (ORCID 0000-0002-5370-8438).

2 Ferreyra, Raúl Gustavo. (2016). "Notas sobre derecho constitucional y garantías", Ciudad Autónoma de Buenos Aires, Ed. Ediar, p. 185-186.
} 
sociales, trabajo, incluso amistades, afectos y creencias religiosas y políticas por el peligro de enfermarse. La vida desnuda, y el miedo a perderla, no es algo que une a los hombres, sino que los enceguece y los separa."

El miedo y el temor tienen dimensiones distintas, según el alcance $o$ afecte a uno o varios individuos de una sociedad. Espinoza Rojas sostiene que: "...las últimas décadas fueron marcadas por eventos cataclísmicos que auguraban una época oscura venidera: la gripe aviar, la gripe $\mathrm{AH} 1 \mathrm{~N} 1$, grandes terremotos y tsunamis, guerras, etc. Sin embargo, quizás uno de estos eventos más importantes fue el 11 de setiembre, el cual trajo consigo el miedo colectivo al terrorismo y sus consecuencias..."

El miedo colectivo ha transformado el mundo, y con él aspectos esenciales de los derechos fundamentales. El miedo generado por el $11 S$ restringió de una manera impensada a fines del siglo XX el derecho a la privacidad de los individuos, hoy la seguridad y las medidas de prevención contra el terrorismo colocan a todas las personas en un estado de sospecha que permite al Estado coartar o restringir los derechos individuales. El miedo colectivo cambió el peso de los derechos en el 2001.

A fin de avanzar en el concepto del miedo colectivo, explica Barrera Méndez:

"Un miedo colectivo es miedo compartido por una parte importante de un grupo o de una sociedad. Para fines pedagógicos se puede observar que el miedo, el pánico y el miedo colectivo son variaciones de temor, en diferentes niveles de análisis (individual, grupal, intergrupal o colectivo), y es una emoción intensa compartida por un grupo o sociedad ante la percepción de un estímulo amenazante, cuyas fuentes pueden ser: psicosociales, políticas,

\footnotetext{
3 Agamben, Giorgio. (2020). "CHIARIMENTI", en https://www.quodlibet.it/giorgioagamben-chiarimenti. Traducción realizada por Martina Bisio.

4 Espinoza Rojas, Johan. (2017). "Breves reflexiones sobre las imágenes del miedo al fin del mundo: el caso de las pandemias en la pantalla". Revista De Filosofía De La Universidad De Costa Rica, 56(145), en https://revistas.ucr.ac.cr/index.php/filosofia/article/view/28260
} 
económicas, culturales, espirituales, del cuidado de la salud, de manipulación de los medios de comunicación o más."

Dupuy expone el pensamiento de L. Crocq (escuela Francesa) quien define al pánico como:

"Miedo colectivo intenso, sentido simultáneamente por todos los individuos de una población, caracterizado por la regresión de las conciencias a un estadio arcaico, impulsivo y gregario, que se traduce en reacciones de desbandada de agitación desordenada, de violencia o de suicidio colectivo".

Korstanje, siguiendo a Dupuy, explica que para la escuela Americana el pánico es mucho menos irracional y salvaje:

"no es de extrañar que en la mayor parte de las situaciones de caos y crisis se esté muy lejos del pánico en sí mismo. Si bien éste implica un proceso de ruptura con las normas sociales, re-socialización, no sugiere la posibilidad de una individualización extrema. En estos estados colectivos, el sujeto no regresa a su estadio arcaico animal (como supone la escuela francesa) como así tampoco se encuentra sujeto a los instintos más primitivos, sino guiado por un intenso miedo busca una solución racional; es precisamente cuando no encuentra la salida o alternativas cuando se torna preso de la irracionalidad." 7

El miedo colectivo debe necesariamente ser contenido debido a que si es llevado a sus extremos más irracionales puede tornarse en un factor social disgregante.

5 Barrera Méndez, Juan Antonio (2010). “El miedo colectivo: el paso de la experiencia individual a la experiencia colectiva", Distrito Federal - México Universidad Autónoma Metropolitana Unidad Azcapotzalco, El Cotidiano, núm. 159, enero-febrero, 2010, pp. 5-10, en http://www.redalyc.org/articulo.oa?id=32512747002.

6 Dupuy, Jean-Pierre (1999). "El pánico", Barcelona Ed. Gedisa, traducción Marta Bris Marino y Ramon Ardell Argíles, p. 41

7 Korstanje, Maximiliano E. (2009)."Pánico y mercado: contribuciones y limitaciones de Jean-Marie Dupuy al estudio del terror financiero" en Contribuciones a la Economía, julio 2009 en http://www.eumed.net/ce/2009b/mek.htm 
Para calmar el miedo es necesario que exista una sensación de seguridad. Sentirse seguro y protegido nos rememora a nuestra niñez, a esa protección paternal en la cual si se siguen los consejos dados nada malo sucederá.

Los problemas que acarrea el COVID-19 son nuevos e incipientes y su solución no se avizora como próxima. En materia sanitaria la pandemia no ha terminado, sino que estamos imbuidos en ella y aún no se conoce cuál será su extensión. En materia económica los impactos actuales producen alarma y preocupación, no sólo por la magnitud del daño que producirá sino también por el tiempo en que se demorará en conjurar el mismo. Finalmente esperemos que la crisis sanitaria y económica no desemboquen en crisis sociales.

En este contexto, rodeados por el temor social, los Estados intentan darnos seguridad mediante reglas que nos protegen de nuestra propia desidia, con un control y cuidado ante dicho incumplimiento.

\section{Zaffaroni dice que}

"En primer lugar, la invocación permanente de la emergencia como razón de Estado se remonta a Hobbes: ante cualquier arbitrariedad del Estado, es preferible sufrirla a optar por la resistencia, pues con ella desaparece la autoridad y se produce la guerra de todos contra todos."

Recientemente Boaventura de Sousa Santos afirmaba:

"Existe un debate en las ciencias sociales sobre si la verdad y la calidad de las instituciones de una determinada sociedad se conocen mejor en situaciones de normalidad, de funcionamiento corriente, o en situaciones excepcionales, de crisis".

\footnotetext{
8 Zaffaroni, Eugenio Raúl (2003). Prologo en Ferreyra, Raúl Gustavo. (2003). “La constitución vulnerable. Crisis argentina y tensión interpretativa". Ed. Ed.Hammurabi, p. 10

9 Boaventura de Sousa Santos (2020). "Coronavirus: todo lo sólido se desvanece en el aire...", Diario Página 12, 17 de marzo de 2020, https://www.pagina12.com.ar/253465coronavirus-todo-lo-solido-se-desvanece-en-el-aire
} 
Hoy, en el medio de esta crisis, se busca analizar la misma mirando las herramientas que ha previsto la Constitución para estos tiempos, lo cual dará un marco para ir evaluando su funcionamiento y capacidad para conjurar el miedo.

\section{La emergencia en la Constitución Federal Argentina}

La Constitución Federal Argentina (CFA) 1853-60 reguló la emergencia únicamente en dos institutos, la intervención federal y el estado de sitio. En este sentido los artículos 6 y 23 de la CFA, receptaron dichos institutos los cuales fueron ampliamente utilizados. La característica, en común, de los mismo es que ambos se vinculan con hechos sociales.

Dichos artículos, no parecen adecuados para dar respuesta a la situación que hoy se está viviendo. Sólo la existencia de una desobediencia social relevante a las disposiciones dictadas para preservar la salud, podrían habilitar a la declaración del estado de sitio por las vías constitucionales. En relación con la intervención federal, para la aplicación de esta debería estar en peligro el funcionamiento republicano de sus instituciones.

En este breve repaso no podemos dejar de recordar que la reforma constitucional de 1949, creó el instituto de estado de prevención y alarma10.

10 El art. 34 establecía "En caso de conmoción interior o de ataque exterior, que ponga en peligro el ejercicio de esta Constitución y de las autoridades creadas por ella, se declarará en estado de sitio la provincia o territorio en donde exista la perturbación del orden, quedando suspensas allí las garantías constitucionales. Pero durante esta suspensión no podrá el presidente de la República condenar por sí ni aplicar penas. Su poder se limitará en tal caso, respecto de las personas, a arrestarlas o trasladar las de un punto a otro de la Nación, si ellas no prefiriesen salir del territorio argentino. Podrá declararse asimismo el estado de prevención y alarma en caso de alteración del orden público que amenace perturbar el normal desenvolvimiento de la vida o las actividades primordiales de la población. Una ley determinará los efectos jurídicos de tal medida, pero ésta no suspenderá, sino que limitará transitoriamente las garantías constitucionales en la medida que sea indispensable. Con referencia a las personas, los poderes del presidente se reducirán a detenerlas o trasladarlas de un punto a otro del territorio, por un término no mayor de treinta días.". Monti, Natalia (2015). "Constituciones Argentinas. Compilación histórica y análisis doctrinario", Buenos Aires, Ed. SAIJ, p 203. 
La figura del estado de prevención y alarma no tuvo efectiva aplicación durante su vigencia. La misma era una figura de menor impacto que el estado de sitio y para situaciones menos graves y no requería para su aplicación por parte del Poder Ejecutivo, la existencia de una conmoción que afectara a la Constitución o a las autoridades.

Expresamente el texto constitucional hablaba de una "alteración del orden público que amenace perturbar el normal desenvolvimiento de la vida o las actividades primordiales de la población”.

Dicha descripción parece ajustarse a lo que sucede en la actualidad con la crisis generada por la irrupción del virus COVID-19.

El Ejecutivo podía establecerlo por tiempo limitado, afectando ello a todo el territorio del país o a parte de este, debiendo dar cuenta al Congreso (art. 83, inc. 19). El Congreso debía reglamentar mediante una ley los efectos jurídicos de la medida.

Dicho instituto fue motivo de duras críticas, pero de forma coincidente con Dalla Vía ${ }^{11}$ se puede afirmar que las críticas doctrinarias a este instituto se fundamentaron más en la desconfianza respecto de su abuso o mala aplicación, que a las características propias de la previsión del estado de excepción y alarma.

Sobre la utilización histórica de la emergencia en argentina, Ferreyra expone:

"La "emergencia pública" tiene poca asociación con el derecho de la revolución triunfante. Empieza aproximadamente en 1920 y continúa en nuestros días. Casi todos los gobiernos constitucionales apelaron a ella, cuyo resultado más evidente fue o la suspensión o la frustración -según el caso- de derechos subjetivos de raíz constitucional. Existe una emergencia finita que

11 Dalla Via, Alberto Ricardo (2004). "Manual de Derecho Constitucional", Buenos Aires, LexisNexis, p. 272. 
juega dentro de la Ley Fundamental; otra, carece de propiedades jurídicas, todo lo desjuridiza, porque provoca distorsiones profundas en la regla de reconocimiento, trayendo como testimonio inmediato y evidente la no observación de fragmentos constitucionales. Esta emergencia descripta como infinita, porque no tiene término, provoca que la regla conceptual deja de ser la democracia; no es la decisión del pueblo la que decide la alteración de sus propios derechos fundamentales. ${ }^{12}$

D'Ors exponiendo en relación con el estado de excepción comenta:

"Ha sido siempre una grave cuestión - decía Abraham Lincoln en un discurso de 1864 - la de si un gobierno que no resulte demasiado fuerte para las libertades de su pueblo puede ser lo suficientemente fuerte para mantener su existencia en grandes emergencias... la concentración del poder en una sola persona había sido siempre una necesidad en los momentos de emergencia pública... pero el problema estaba en que aquel poder excepcional tendía por sí mismo a prorrogar el estado de excepción... Entre estos dos términos, la necesidad originaria y la perduración subsiguiente, está el problema político todo del estado de excepción"13

\section{Luego agrega:}

"En efecto, el poder excepcional puede presentarse como un elemento extraño en la constitución, que irrumpe en su vida desde fuera y suspende su vigencia, o como un elemento intrínseco a la misma, ya que la constitución puede tener prevista una solución para los casos de emergencia. En este segundo caso, el poder excepcional no suspende la constitución misma, sino que la realiza

\footnotetext{
12 Ferreyra, Raúl Gustavo (2006). "Poder, democracia y configuración constitucional”. Cuadernos Electrónicos, 3. En http://www.circulodoxa.org/documentos/Ferreyra, 2004 (I). pdf, p.39

13 D’ Ors, Álvaro y Pérez-Peix (1961). “Cicerón, sobre el estado de excepción”, Cuadernos de la Fundación Pastor, ISSN 0532-8551, № 3, 1961, pp. 11-31, p. 12.
} 
en una de sus previsiones; el poder de excepción no es entonces menos constitucional que el previsto para la situación considerada como no excepcional. Se trata de un poder excepcional, pero normal. Es más; si la constitución de cualquier pueblo puede servir ante todo como norma preventiva de los peligros que amenazan a la comunidad, ninguna disposición constitucional cumple mejor ese propio fin que aquella en que se provea para los casos de peligro emergente. Nada más constitucional, en este sentido, que las disposiciones que otorgan poderes excepcionales." ${ }^{14}$

La solución constitucional de la reforma de 1994 ha sido reforzar al Poder Ejecutivo en los tiempos de crisis. Se ha buscado regular la situación de emergencia mediante la constitucionalización de dos institutos: la delegación legislativa y los decretos de necesidad y urgencia. La reforma constitucional acentuó notablemente las potestades del presidente ${ }^{15}$.

La solución constitucional argentina no ha sido novedosa. Reforzar al Poder Ejecutivo o a quien detenta al poder, parece ser una solución habitual, aún en estados de naturaleza democrática.

\section{II.1. La constitución reformada y la crisis del año 2001}

En el año 2001, frente a la profunda crisis económica, las herramientas legales utilizadas se caracterizaron por la asignación y utilización por parte del Poder Ejecutivo de poderes propios del Poder Legislativo, ya sea mediante decretos de necesidad y urgencia o decretos delegados. Más aún en el pináculo de la crisis se llegó hasta el dictado del estado de sitio, antes de le renuncia del presidente De la Rúa.

\footnotetext{
14 D’ Ors, Álvaro y Pérez-Peix (1961). "Cicerón..", ob.cit. p. 13.

15 Ferreyra, Raúl Gustavo (2009). "Rasgos de la democracia Argentina eficacia de las garantías constitucionales 1983-2008: división de poderes y democracia delegativa versus protección de la libertad?" en Estudios Constitucionales, año 7 (número2), ps. 255-278, en https://doi.org/10.4067/S0718-5200200900020001, p. 270
} 
Las disposiciones constitucionales no rigieron plenamente en esos momentos, sino que de una u otra forma el Poder Legislativo cedió sus propias facultades al Poder Ejecutivo, en la idea imaginaria o mística de que un Poder Ejecutivo fuerte puede conjurar por sí sólo cualquier crisis. Pero en aquel momento ello no alcanzo para sortear la crisis y el país sucumbió a finales de aquel año.

La ausencia del congreso en aquel momento mediante su voluntario apartamiento no coadyuvo a superar la crisis.

Es necesario frente a una situación de crisis la profundización de la democracia, y ello requiere necesariamente del funcionamiento del Poder Legislativo. Como expresa Zaffaroni "Contra la crisis, más democracia" ${ }^{16}$.

Se comparte lo que señala Ferreyra ${ }^{17}$ en cuanto a que a través del proceso de producción legal el Congreso debe cooperar con la autodirección política de la sociedad, a la que sus miembros representan.

\section{Política y crisis}

La dinámica política de la crisis no sólo pone en contraste la velocidad con la cual pueden tomar decisiones el Poder Ejecutivo y el Poder Legislativo, sino que también -en ocasiones- hace aflorar las pequeñeces de la política ${ }^{18}$.

La emergencia produce una situación en la cual es conveniente para el Poder Legislativo ceder sus poderes (o no ejercerlos) y al Poder Ejecutivo le conviene recibirlos. Para el legislativo

16 Zaffaroni, Eugenio Raúl (2002). "Contra la crisis, más democracia”, Diario Clarín, Buenos Aires.

17 Ferreyra, Raúl Gustavo (2003). “La constitución vulnerable. Crisis argentina y tensión interpretativa." Buenos Aires, Hammurabi, p. 62.

18 Un ejemplo actual de ello ha sido la denominada "travesía por la democracia" mediante la cual un grupo de diputados se oponía a las sesiones virtuales planteando su ilegalidad. Véase una reseña periodística en https://www.lapoliticaonline.com/nota/126160-travesiapor-la-democracia-el-viaje-de-los-diputados-de-cambiemos-para-sesionar-en-cuarentena/ 
significa desprenderse de la responsabilidad de participar en la resolución de la crisis, éste cede sus poderes al ejecutivo y de ese modo se deshace de la responsabilidad política. El ejecutivo puede tomar decisiones autónomas sin consultar a nadie, y si logra sortear la crisis el éxito es todo propio. La delegación o la convalidación del uso de poderes de urgencia es conveniente para ambos.

Ferreyra señala que:

"El congreso se encuentra diseñado constitucionalmente para cumplir su privilegiada función de vehículo y caja de resonancia de la representación y opinión popular, respectivamente. Cuando estas transmisiones, repercusiones o intermediaciones no se dan, o cuando los órganos legislativos no saben, no quieren o no pueden interpretar los requerimientos y peticiones populares, se produce un notable alejamiento entre los representantes y sus representados que es sumamente peligroso"19

Ahora bien, es importante que esa caja de resonancia durante las crisis funcione más que nunca, si ello no ocurre la opinión publica queda condicionada a la que exponen los medios de comunicación ${ }^{20}$.

Pero esta situación no es novedosa, explica Ferreyra que:

"Tampoco las grandes conmociones mundiales tuvieron a los parlamentos y congresos como cajas de resonancia del sentir de las expresiones ciudadanas, y consecuentemente no jugaron un rol institucional sobresaliente en su representación; ni por supuesto tampoco, en la solución de las consecuencias del flagelo"21

Si bien la propia CFA habilita dicha situación ya que al regularlo lo hace de una manera laxa.

\footnotetext{
19 Ferreyra, Raúl Gustavo (2016). "Notas..." ob. cit., p. 203.

20 En este sentido Ferreyra advierte de ello. Véase Ferreyra, R. G. (2016). “Notas... " ob. cit., p. 203.

21 Ferreyra, Raúl Gustavo (2016). “Notas..." ob. cit., p. 212.
} 
El funcionamiento del Congreso, aunque sea en forma esporádica, revisando las medidas adoptadas por el Poder Ejecutivo en uso de atribuciones extraordinarias y legislando sobre temas de emergencia da institucionalidad en el medio de la emergencia.

Esa institucionalidad tranquiliza y aleja el miedo.

Hoy, transitando esta etapa primigenia de la crisis y con el Congreso buscando la forma de funcionar, el Poder Ejecutivo a fin de obtener la institucionalidad se apoyó en los Gobernadores ${ }^{22}$. Así todas las presentaciones relevantes las hizo junto a ellos, y esa imagen de institucionalidad trajo algo de tranquilidad.

\section{Duración de la crisis}

Walter Benjamín fue el primero ${ }^{23}$ en caracterizar la existencia de un estado de excepción permanente. El citado autor en su octava tesis señala: "La tradición de los oprimidos nos enseña que el 'estado de excepción' en el cual vivimos es la regla. Debemos adherir a un concepto de historia que se corresponda con este hecho"24.

Agamben señala:

"...desde el momento en que "el estado de excepción [...] ha devenido en la regla" (Benjamin, 1942, p. 697), no sólo se presenta cada vez más como una técnica de gobierno y no como una medida excepcional, sino que inclusive deja también salir a la luz su naturaleza de paradigma constitutivo del orden jurídico." ${ }^{25}$.

Agamben cita a Rossiter quien expresó:

"Al describir los gobiernos de emergencia en las democracias occidentales, este libro pudo haber dado la impresión

\footnotetext{
22 Recordemos que la CFA establece "Artículo 128.- Los gobernadores de provincia son agentes naturales del Gobierno federal para hacer cumplir la Constitución y las leyes de la Nación.".

23 Agamben, Giorgio (2005). "Estado de excepción. Homo sacer, II, I.",F. C. Costa, Trad., Buenos Aires, Adriana Hidalgo editora, p. 36

24 Benjamin Walter, citado por Agamben, Giorgio (2005). "Estado...", ob. cit., p. 111.

25 Agamben, Giorgio (2005). "Estado...", ob. cit., p. 32.
} 
de que las técnicas de gobierno tales como la dictadura del ejecutivo, la delegación de los poderes legislativos y la legislación a través de decretos administrativos son por naturaleza puramente transitorias y temporarias. Una impresión tal sería ciertamente equívoca [...]. Los instrumentos de gobierno aquí descriptos como dispositivos temporarios de crisis han devenido en algunos países, y pueden devenir en todos, instituciones durables y permanentes inclusive en tiempos de paz". ${ }^{26}$

Las situaciones relatadas por estos autores permiten reflejar lo que ha sucedido en argentina desde la década de 1980.

La reforma de 1994 como se expuso anteriormente recepta la emergencia dentro de su texto. Para ello utiliza una técnica criticable, prohíbe la delegación legislativa (art. $76 \mathrm{CN})^{27}$ y prohíbe el dictado de decretos de necesidad y urgencia (art. 99 inc. $3 \mathrm{CN})^{28}$, para luego de tan tajantes prohibiciones habilitar la delegación y el dictado de decretos de necesidad y urgencia mediante fórmulas poco claras ${ }^{29}$. Coincidentemente con Ferreyra se puede afirmar que ambos son instrumentos de franca naturaleza legislativa, siendo ello una competencia constitucional atribuida al Congreso. ${ }^{30}$

Agamben sostiene que el estado de excepción es ese momento del derecho en el que se suspende el derecho precisamente

\footnotetext{
26 Agamben, Giorgio (2005). “Estado ...", ob. cit., p. 36.

27 Se prohíbe la delegación legislativa en el Poder Ejecutivo

28 El Poder Ejecutivo no podrá en ningún caso bajo pena de nulidad absoluta e insanable, emitir disposiciones de carácter legislativo.
}

29 Bianchi afirma "Basta con leer el Artículo 76 para advertir que se trata de una disposición poco clara." (Bianchi, A. B. (2015). "La delegación legislativa: evolución y estado actual", 3. Forum. Anuario del Centro de Forum de Derecho Constitucional, en http://bibliotecadigital. uca.edu.ar/repositorio /revistas/delegacion-legislativa-evolucion-estado.pdf, p. 26.)

Bidart Campos por su parte señala "La excepción permisiva viene concedida para "materias determinadas de administración" o de "emergencia pública". Las expresiones son harto vagas y muy poco concisas, por lo que tememos que se las invoque en demasía con cualquier pretexto y con escasa precisión." (Bidart Campos, German (2001). “Manual de la Constitución Reformada", Tomo 3. Buenos Aires: Ediar, p. 155)

30 Ferreyra, Raúl Gustavo (2016). “Notas...”, ob .cit. p. 214 nota al píe No 30. 
para garantizar su continuidad, e inclusive su existencia. O también: la forma legal de lo que no puede tener forma legal, porque es incluido en la legalidad a través de su exclusión ${ }^{31}$. Así se suspende por vía de excepción la aplicación del derecho, con un fin superior que es el mantenimiento de la sociedad.

Hablando sobre las implicancias del COVID-19, Agamben ${ }^{32}$ afirma que la epidemia deja en claro que el estado de excepción se ha convertido realmente en la condición normal. Así introduce dos nuevos conceptos, crisis perenne y emergencia perenne afirmando que la sociedad que vive en un estado de emergencia perenne no puede ser una sociedad libre.

Cabe preguntarse si el art. 76 y 99 inc. 3 de la CFA son esas válvulas de escape que presenta el propio sistema constitucional para garantizar su mantenimiento. La realidad demuestra que esas válvulas de escape funcionan en tiempos de crisis, pero el problema ha sido su cierre. Por una u otra razón existen urgencias o emergencias que las mantienen abiertas.

La realidad a las que hoy nos enfrenta el COVID-19 nos muestra que los efectos del virus en materia sanitaria y en materia económica han llegado para quedarse un tiempo que no será corto, y en ese proceso hasta el 12 de abril de 2020 (un mes de la declaración de emergencia por el COVID-19) se dictaron 19 decretos de necesidad y urgencia.

\section{Emergencia}

La emergencia es un estado dentro del cual la constitución debe adquirir una centralidad máxima. Tal es así que, aún con los defectos señalados, ella provee herramientas que pueden ser utilizadas para conjurar la emergencia y también establecer controles. Además, dichas herramientas sólo pueden ser válidamente utilizadas en la medida que no abroguen derechos fundamentales.

31 Flavia Costa en la introducción de Agamben, Giorgio. (2005). “Estado...", p. 5

32 Agamben, Giorgio (2020). "CHIARIMENTI", ob. cit. 
Puede afirmarse que emergencias como la provocada por el COVID-19 ponen a prueba al texto constitucional y a la institucionalidad.

Es dable recordar la caracterización de la emergencia para luego evaluar la magnitud de los poderes para conjurarla.

Häberle afirma que:

"La finalidad del "estado de excepción" o la llamada "emergencia de Estado" es también la protección de la Constitución. Se trata de todos los peligros graves para la permanencia del Estado o de la seguridad y el orden públicos, lo que no puede resolverse mediante las vías normales previstas por la Constitución, sino que su defensa y medidas solamente son posibles con medios excepcionales..."33

La Corte Argentina ha caracterizado la emergencia como aquellas situaciones que:

“... derivan de acontecimientos extraordinarios, imprevisibles o bien, inevitables con los recursos ordinarios $y$ que tienen una repercusión muy honda y extensa en la vida social, de suerte que demandan remedios, también, extraordinarios: a veces, son acontecimientos de carácter físico (terremotos, epidemias), económico, social o político (como una revolución), pero lo que tipifica la existencia o no de la emergencia " no es la naturaleza del hecho determinante, sino su modo de ser extraordinario, la gravedad $y$ amplitud de sus efectos y la necesidad imperiosa de establecer normas adecuadas para restablecer los intereses públicos afectados" ${ }^{34}$.

En "Peralta" la Corte Suprema dijo que, una emergencia requiere que exista una situación de emergencia que imponga al Estado el deber de amparar los intereses vitales de la comunidad ${ }^{35}$.

\footnotetext{
33 Häberle, Peter (2016). "El Estado Constitucional", México, Universidad Autónoma de México, p. 274.

34 CSJN (1957). "Perón, Juan Domingo", 21/07/1957, Fallos 238:76.

35 CSJN (1990). “Peralta, Luis Arcenio y otro c/ Estado Nacional (Mrio. de Economía BCRA.) s/ amparo", 27/12/1990, Fallos 313:1513.
} 
Hernández analizando el tema indica:

“...los distintos elementos que caracterizan la emergencia: a) son situaciones excepcionales, previsibles o no, que afectan el orden constitucional; b) los hechos que las producen pueden ser originados en diversas causas: políticas, económicas, sociales o de la naturaleza; c) para enfrentar estos hechos, el derecho crea diversas instituciones de emergencia, que varían según las legislaciones; d) estas instituciones producen un acrecentamiento de facultades en los poderes estatales y particularmente en el Ejecutivo y correlativamente, un descaecimiento o restricciones en los derechos y garantías individuales;

e) debe existir un verdadero estado de necesidad" 36 .

Ha existido un intento de la justicia en distintos niveles en definir ontológicamente cuando puede considerarse que existe emergencia, pero las definiciones han sido sinuosas y con cierto dejo de vaguedad.

La emergencia provocada por el COVID19 no genera dudas en cuanto a que se trata de una situación de excepción, de extrema gravedad y urgencia.

\section{Magnitud de los poderes de emergencia del Estado Federal}

Sin lugar a duda hoy se está frente a una situación que ha desdibujado los límites habitualmente preconcebidos frente a una hipotética situación de emergencia. Como se expuso, frente a la existencia de la emergencia el Poder Ejecutivo Nación echó mano a uno de los mecanismos constitucionalmente previstos, los Decretos de Necesidad y Urgencia (CFA art. 99 inc. 3)

Como expresa la frase popular, la realidad supera a la ficción, y siempre que se analizan o estudian poderes de emergencia,

\footnotetext{
36 Hernández, A. M. (2003). "Las emergencias y el orden constitucional” , Vol. Serie Estudios jurídicos, Núm. 47, México, Ed. Universidad Nacional Autónoma de México, Instituto de Investigaciones Jurídicas: Rubinzal-Culzoni editores, en https://biblio.juridicas.unam.mx/ bjv/detalle-libro/1082-las-emergencias-y-el-orden-constitucional-2a-ed, p. 7.
} 
surgen como hipótesis de su aplicación situaciones de urgencia o gravedad, ya sean estas derivadas de hechos más cercanos a la naturaleza (vgr terremotos) o de otras circunstancias (vgr crisis económica), en la que se adoptarían medidas de emergencias que restringirían generalmente ciertos derechos. Por lo general no surgen de dicho análisis la posibilidad de limitar libertades individuales básicas de las personas, y menos por un largo tiempo.

Sagüés afirma "La constitución de poder restringido o moderado reconoce un amplio espectro de derechos personales, sin perjuicio de su restricción en situaciones de emergencia, pero encuadrando esas limitaciones según pautas de razonabilidad"37. En estos tipos constitucionales se admitiría la limitación o restricción de los derechos personales en función de situaciones de emergencia.

Ferreyra explica que "La libertad constitucional de cada hombre está limitada por la libertad de los demás, por la seguridad de todos y por las justas exigencias del bienestar general y del desenvolvimiento democrático." 38 .

En época de emergencias esas limitaciones pueden ser más profundas, pero no suprimidas.

\section{VI.1. Emergencia y Pactos}

La centralidad del texto constitucional en tiempos de emergencia no se limita o circunscribe a las cláusulas constitucionales de emergencia que regulan los institutos, sino a todo el plexo constitucional.

La reforma de 1994 de la CFA, coetáneamente a la constitucionalización de nuevos institutos vinculados a la emergencia, modificó el artículo 75 inc. 22 que incorpora a los tratados de Derechos Humanos como parte del conjunto de derechos, deberes y garantías constituciones.

37 Sagüés, Nestor. Pedro (2007). "Manual de derecho constitucional”, Buenos Aires, Ed. Astrea, p. 57.

38 Ferreyra, Raúl Gustavo (2009). "Rasgos ..." ob. cit. p. 267. 
Por ello se nos exige en esto tiempos de crisis analizar someramente cuales son las previsiones que los tratados contienen para situaciones de emergencia, dado que su observación es inexcusable.

La Declaración Americana de los Derechos y Deberes del Hombre en su artículo XXVIII expresa:

"Los derechos de cada hombre están limitados por los derechos de los demás, por la seguridad de todos y por las justas exigencias del bienestar general y del desenvolvimiento democrático..." ${ }^{\prime 39}$

El Pacto internacional de Derechos Civiles y Políticos ${ }^{40}$ establece:

"Artículo $4^{\circ}$

1. En situaciones excepcionales que pongan en peligro la vida de la nación y cuya existencia haya sido proclamada oficialmente, los Estados Partes en el presente Pacto podrán adoptar disposiciones que, en la medida estrictamente limitada a las exigencias de la situación, suspendan las obligaciones contraídas en virtud de este Pacto, siempre que tales disposiciones no sean incompatibles con las demás obligaciones que les impone el derecho internacional y no entrañen discriminación alguna fundada únicamente en motivos de raza, color, sexo, idioma, religión u origen social.

2. La disposición precedente no autoriza suspensión alguna de los artículos 6, 7, 8 (párrafos 1 y 2), 11, 15, 16 y 18.

3. Todo Estado Parte en el presente Pacto que haga uso del derecho de suspensión deberá informar inmediatamente a los demás Estados Partes en el presente Pacto, por conducto del Secretario General de las Naciones Unidas, de las disposiciones cuya aplicación haya suspendido y de los motivos que hayan suscitado la suspensión. Se hará

39 http://www.oas.org/es/cidh/mandato/Basicos/declaracion.asp

40 https://www.ohchr.org/SP/Professionallnterest/Pages/CCPR.aspx 
una nueva comunicación por el mismo conducto en la fecha en que se haya dado por terminada tal suspensión. Observación general sobre su aplicación"
El Pacto Internacional de Derechos Económicos, Sociales y Culturales ${ }^{41}$ en su artículo $4^{\circ}$ prevé:
"Los Estados Partes en el presente Pacto reconocen que, en ejercicio de los derechos garantizados conforme al presente Pacto por el Estado, éste podrá someter tales derechos únicamente a limitaciones determinadas por ley, sólo en la medida compatible con la naturaleza de esos derechos y con el exclusivo objeto de promover el bienestar general en una sociedad democrática."

Por su parte la Declaración Universal de Derechos Humanos $^{42}$ establece en su art. 29.2 que:

"En el ejercicio de sus derechos y en el disfrute de sus libertades, toda persona estará solamente sujeta a las limitaciones establecidas por la ley con el único fin de asegurar el reconocimiento y el respeto de los derechos y libertades de los demás, y de satisfacer las justas exigencias de la moral, del orden público y del bienestar general en una sociedad democrática".

La Convención Americana sobre Derechos Humanos en su artículo $27^{\circ}$ estipula:

"En caso de guerra, de peligro público o de otra emergencia que amenace la independencia o seguridad del Estado parte, éste podrá adoptar disposiciones que, en la medida y por el tiempo estrictamente limitados a las exigencias de la situación, suspendan las obligaciones contraídas en virtud de esta Convención, siempre que tales disposiciones no sean incompatibles con las demás obligaciones que les impone el derecho internacional y no entrañen discriminación alguna fundada en motivos de raza, color, sexo, idioma, religión u origen social..."

\footnotetext{
41 https://www.ohchr.org/SP/Professionallnterest/Pages/CESCR.aspx

42 https://www.un.org/es/universal-declaration-human-rights/
} 
La Corte Interamericana en la Opinión Consultiva ("OC") 8/87 dice que "no se trata de una 'suspensión de garantías' en sentido absoluto" y aclara que "lo único que podría suspenderse o impedirse sería [el] pleno y efectivo ejercicio [de los derechos]" 43 .

Para la Protección de Derechos Humanos y Libertades Fundamentales, el Consejo de Europa, permite que se tomen medidas que deroguen las obligaciones del Convenio en el caso de guerra o de otro peligro público que amenace la vida de la Nación, con exclusiones parecidas a las del Pacto Internacional.

La Convención contra la Tortura y Otros Tratos o Penas Crueles, Inhumanos o Degradantes establece:

"Artículo $2^{\circ}$

1. Todo Estado Parte tomará medidas legislativas, administrativas, judiciales o de otra índole eficaces para impedir los actos de tortura en todo territorio que esté bajo su jurisdicción.

2. En ningún caso podrán invocarse circunstancias excepcionales tales como estado de guerra o amenaza de guerra, inestabilidad política interna o cualquier otra emergencia pública como justificación de la tortura."

La Convención interamericana sobre desaparición forzada de personas dispone:

"Articulo I

Los Estados Partes en esta Convención se comprometen a:

a) No practicar, no permitir, ni tolerar la desaparición forzada de personas, ni aun en estado de emergencia, excepción o suspensión de garantías individuales;...

Articulo X

\footnotetext{
43 Levi, Daniel (2013). "Art. 27. Suspensión de garantías" en Alonso Regueira, Enrique M. (2013). “La Convención Americana de Derechos Humanos y su proyección en Derecho Argentino", Buenos Aires, Ed. La Ley, p. 481
} 
En ningún caso podrán invocarse circunstancias excepcionales, tales como estado de guerra o amenaza de guerra, inestabilidad política interna o cualquier otra emergencia pública, como justificación de la desaparición forzada de personas. En tales casos, el derecho a procedimientos o recursos judiciales rápidos eficaces se conservará como medio para determinar el paradero de las personas privadas de libertad o su estado de salud o para individualizar a la autoridad que ordenó la privación de libertad o la hizo efectiva.

En la tramitación de dichos procedimientos o recursos y conforme al derecho interno respectivo, las autoridades judiciales competentes tendrán libre e inmediato acceso a todo centro de detención y a cada una de sus dependencias, así como a todo lugar donde haya motivos para creer que se puede encontrar a la persona desaparecida, incluso lugares sujetos a la jurisdicción militar.

La Convención Internacional sobre los Derechos de las Personas con Discapacidad

Artículo $11^{\circ}$. Situaciones de riesgo y emergencias humanitarias

Los Estados Partes adoptarán, en virtud de las responsabilidades que les corresponden con arreglo al derecho internacional, y en concreto el derecho internacional humanitario y el derecho internacional de los derechos humanos, todas las medidas necesarias para garantizar la seguridad y la protección de las personas con discapacidad en situaciones de riesgo, incluidas situaciones de conflicto armado, emergencias humanitarias y desastres naturales.

Los restantes tratados incorporados ${ }^{44}$ no estipulan previsiones algunas al respecto.

44 Ellos son: 1) Convención para la Prevención y la Sanción del Delito de Genocidio, 2) Convención Internacional sobre la Eliminación de todas las Formas de Discriminación Racial, 3) Convención sobre la eliminación de todas las formas de discriminación contra la mujer, y 4) Convención sobre la imprescriptibilidad de los crímenes de guerra y de los crímenes de lesa humanidad. 


\section{VI.2. Finalidad, alcance y controles de las medidas}

Hamilton en el Federalista sostenía

"Si el gobierno nacional se viera en uno de esos casos de emergencia, no habría otro medio que el de la fuerza. Los medios que se pongan en juego deben guardar proporción con la importancia del mal." ${ }^{45}$

"La seguridad contra los peligros externos es el más poderoso impulsor de la conducta nacional, y pasando el tiempo, hasta el amor a la libertad acaba por ceder a sus dictados. La destrucción violenta de las vidas y propiedades inherente a la guerra, el esfuerzo continuo y la alarma que acompaña a un estado de constante peligro, obligarán a las naciones más apegadas a la libertad, a buscar la seguridad y el descanso en instituciones que tienden a destruir sus derechos civiles y políticos. Para estar más seguras, acaban por estar dispuestas a correr el riesgo de ser menos libres. ${ }^{46}$ (la negrita es agregada)

Estas dos afirmaciones de Hamilton, con más de doscientos años de antigüedad, mantienen su vigencia. Dos aspectos valen la pena destacar de los pasajes transcriptos, el primero, que aún en la emergencia los medios para conjurarla deben ser razonables y guardar proporción con la importancia del mal, y el segundo que aún las naciones más libres frente al peligro estarán dispuestas a ser menos libres a cambio de ser seguras.

Claro ejemplo de esto último fue lo ocurrido en el mundo luego del 11S.

Retomando con el alcance de las medidas frente a la emergencia, es interesante traer a colación a Häberle quien afirma:

“...El objetivo de cualquier disposición sobre situaciones de emergencia debe ser el restablecimiento, tan

\footnotetext{
45 Hamilton, Alexander, Madison, James, y Jay, John. (1787). “El Federalista.", XXVIII. (Hamilton).

46 Hamilton, Alexander, Madison, James, y Jay, John. (1787). "El Federalista.", XXVIII (Hamilton).
} 
pronto sea posible, de la 'normalidad constitucional'. La idea de la última ratio o de la prohibición del exceso debe guiar a todas las medidas de excepción, como el quebrantamiento de las competencias normales de los parlamentos en favor del ejecutivo (concentración de poderes) o de la limitación o suspensión temporales de los derechos fundamentales. Bajo estas estrictas condiciones requiere la primacía de la Constitución escrita, suspender en partes la Constitución, 'a fin de poder restablecer su vigencia ilimitada'. Es en esta medida que el estado de excepción forma parte plenamente de las instituciones 'normales' del Estado constitucional y no se encuentra, per se, en contradicción con él." ${ }^{\not 7}$

El máximo tribunal en relación con las medidas para combatir las situaciones de emergencia en el precedente "Tobar" ha señalado:

"Las medidas tendientes a conjurar la crisis deben, pues, ser razonables, limitadas en el tiempo, un remedio y no una mutación de la sustancia o esencia de la relación jurídica y están sometidas al control jurisdiccional de constitucionalidad, toda vez que la emergencia, a diferencia del estado de sitio, no suspende las garantías constitucionales (Fallos: 243:467; 323:1566; 323:2492 y pronunciamiento del 1 de febrero de 2002 en la causa B.32.XXXVIII PVA "Banco de Galicia y Buenos Aires s/ solicita intervención urgente en autos: "Smith, Carlos Antonio c/ Poder Ejecutivo Nacional o Estado Nacional s/ sumarísimo", y voto concurrente del juez Fayt)" ${ }^{48}$.

Ferreyra $^{49}$ haciendo un análisis de la función del máximo tribunal afirma que prácticamente a partir de 1920, en casi todas las décadas, la CSJN ha dictado, por lo menos, un

\footnotetext{
47 Häberle, Peter (2016). “El Estado..." ob. cit., p. 274

48 CSJN (2002). “Tobar, Leónidas c/ Estado Nacional -Ministerio de Defensa- Contaduría General del Ejército - Ley 25.453 s/ amparo ley 16.986", 22/08/2002, Fallos: 325:2059, cons. 8.
}

49 Ferreyra, Raúl Gustavo (2006). “Poder...", ob. cit., p. 39 véase en especial nota 55. 
pronunciamiento sobre emergencia y Constitución, y que ellos han justificado la adopción jurídica de remedios extraordinarios cuyo rasgo fundamental es la limitación temporal y razonable del ejercicio de los derechos.

Las medidas adoptadas por el Poder Ejecutivo son revisadas en el juego del sistema de frenos y contrapesos, por el Poder Legislativo y por el Poder Judicial.

El art. 99 inc. 3 de la CFA regula claramente que es función de la Comisión Bicameral Permanente la consideración de las decisiones adoptadas mediante decretos de necesidad y urgencia por el Poder Ejecutivo, y con posterioridad a la intervención de la misma corresponde su tratamiento por cada una de las cámaras.

En cuanto al rol del Poder Judicial frente a la emergencia ha dicho la Corte Suprema de Justicia de la Nación:

"La legislación de emergencia responde al intento de conjurar o atenuar los efectos de situaciones anómalas, ya sean económicas, sociales o de otra naturaleza, y constituye la expresión jurídica de un estado de necesidad generalizado, cuya existencia y gravedad corresponde apreciar al legislador sin que los órganos judiciales puedan revisar su decisión ni la oportunidad de las medidas que escoja para remediar aquellas circunstancias, siempre que los medios arbitrados resulten razonables y no respondan a móviles discriminatorios o de persecución contra grupos o individuos. ${ }^{50}$

Entiendo que las medidas adoptar por el poder ejecutivo para afrontar la emergencia deben cumplir los siguientes aspectos:

a) Guardar una razonable proporción entre la medida adoptada y el problema que se busca solucionar.

b) Ser transitorias o prever su revisión temporal. La adopción en tiempo de crisis de medidas de carácter permanente

50 CSJN (2009). "Bankboston N.A. c/ Jane Javier Esteban s/ejecución hipotecaria", 10/11/2009, Fallos 332:2468. 
no sólo no parece a priori como razonable, sino que corre un serio riesgo que una vez que han desaparecidos los motivos que la fundaron se tornen irrazonables y por tanto inconstitucionales.

c) Deberían tener una mínima interferencia sobre los derechos, con ello se quiere señalar que las restricciones o limitaciones que se imponen a los derechos individuales deben ser las mínimas para conjurar el peligro o intentar reducir sus consecuencias.

d) Deberían ser rápidamente revisadas por el poder legislativo.

\section{Conclusiones}

La emergencia del COVID-19 no tiene precedentes y ha infundido un profundo temor en la sociedad.

En este contexto, y en el marco que suministra la propia CFA el Poder Ejecutivo ha asumido su función de líder frente a las emergencias. Por otro lado, el Congreso luego de más de un mes no ha podido lograr los consensos para sesionar a pesar de que la Corte Suprema de Justicia de la Nación en un "paso de comedia" rechazo una acción entablada por la Presidenta de Senado y despejó la certeza sobre la validez de las sesiones virtuales.

Las medidas adoptadas por el Poder Ejecutivo, miradas coetáneamente con el desarrollo de la pandemia y desde la urgencia, no sólo en el contexto argentino sino en el contexto mundial parecerían razonables.

Se aprecia de igual modo que existe un apoyo casi unánime a las restricciones de las libertades frente a la pandemia del COVID-19. Sin dudas el apoyo se funda en dos aspectos, el primero de ellos la existencia de un miedo colectivo frente a un virus declarado en pandemia y el segundo la necesidad de seguridad -en el más amplio de los sentidos- frente a esta situación crítica. 
Cuando pase el tiempo y este nos otorgue otra perspectiva seguramente se podrá realizar un análisis más profundo y meduloso sobre la razonabilidad de las medidas.

Finalmente, esperemos que más pronto que tarde, superemos esta pandemia. Sin duda el mundo ya no será igual. Sin embargo, no se debe permitir que el miedo actual genere restricciones permanentes en los derechos más allá de lo necesarios para superar este terrible mal.

\section{Bibliografía}

Agamben, Giorgio (2005). "Estado de excepción. Homo sacer, II, I.,,F. C. Costa, Trad., Buenos Aires, Adriana Hidalgo editora.

Agamben, Giorgio (2020). "CHIARIMENTI", en https://www.quodlibet.it/giorgio-agamben-chiarimenti. Traducción realizada por Martina Bisio.

Alonso Regueira, Enrique M. (2013). "La Convención Americana de Derechos Humanos y su proyección en Derecho Argentino", Buenos Aires, Ed. La Ley.

Barrera Méndez, Juan Antonio (2010). "El miedo colectivo: el paso de la experiencia individual a la experiencia colectiva", Distrito Federal - México Universidad Autónoma Metropolitana Unidad Azcapotzalco, El Cotidiano, núm. 159, enerofebrero, 2010, pp. 5-10, en http://www.redalyc.org/articulo. oa? id=32512747002.

Bianchi, A. B. (2015). "La delegación legislativa: evolución y estado actual", 3. Forum. Anuario del Centro de Forum de Derecho Constitucional, en http://bibliotecadigital.uca.edu.ar/repositorio /revistas/delegacion-legislativa-evolucion-estado.pdf

Bidart Campos, German (2001). "Manual de la Constitución Reformada", Tomo 3. Buenos Aires, Ediar.

Boaventura de Sousa Santos (2020). "Coronavirus: todo lo sólido se desvanece en el aire...”, Diario Página 12, 17 de marzo de 2020, en https://www.pagina12.com.ar/253465-coronavirus-todo-losolido-se-desvanece-en-el-aire

D’Ors, Álvaro y Pérez-Peix (1961). "Cicerón, sobre el estado de excepción", Cuadernos de la Fundación Pastor, ISSN 05328551, No. 3, 1961, pp. 11-31. 
Dalla Vía, Alberto Ricardo (2004). "Manual de Derecho Constitucional", Buenos Aires, LexisNexis, p. 272.

Dupuy, Jean - Pierre (1999). "El pánico", Barcelona Ed. Gedisa, traducción Marta Bris Marino y Ramon Ardell Argíles.

Espinoza Rojas, Johan. (2017). "Breves reflexiones sobre las imágenes del miedo al fin del mundo: el caso de las pandemias en la pantalla". Revista De Filosofía De La Universidad De Costa Rica, 56(145)., en https://revistas.ucr.ac.cr/index.php/filosofia/article/view/28260

Ferreyra, Raúl Gustavo (2003). "La constitución vulnerable. Crisis argentina y tensión interpretativa." Buenos Aires, Hammurabi.

Ferreyra, Raúl Gustavo (2006). "Poder, democracia y configuración constitucional", Cuadernos Electrónicos, 3, en http://www. circulodoxa.org/documentos/Fefrreyra, 2004 (I).pdf .

Ferreyra, Raúl Gustavo (2009). "Rasgos de la democracia Argentina eficacia de las garantías constitucionales 1983-2008: división de poderes y democracia delegativa versus protección de la libertad?" en Estudios Constitucionales, año 7 (número2), ps. 255-278 en https://doi.org/10.4067/S0718-5200200900020001.

Ferreyra, Raúl Gustavo. (2016). "Notas sobre derecho constitucional y garantías", Ciudad Autónoma de Buenos Aires, Ed. Ediar.

Häberle, Peter (2016). "El Estado Constitucional”, México, Universidad Autónoma de México.

Hamilton, Alexander, Madison, James, y Jay, John. (1787). "El Federalista."

Hernández, A. M. (2003). "Las emergencias y el orden constitucional”, Vol. Serie Estudios jurídicos, Núm. 47, México, Ed. Universidad Nacional Autónoma de México, Instituto de Investigaciones Jurídicas: Rubinzal-Culzoni editores, en https:// biblio.juridicas.unam.mx/bjv/detalle-libro/1082-las-emergencias-y-el-orden-constitucional-2a-ed.

Korstanje, Maximiliano E. (2009).”Pánico y mercado: contribuciones y limitaciones de Jean-Marie Dupuy al estudio del terror financiero" en Contribuciones a la Economía, julio 2009, en http://www.eumed.net/ce/2009b/mek.htm

Monti, Natalia (2015). "Constituciones Argentinas. Compilación histórica y análisis doctrinario.”, Buenos Aires, Ed. SAIJ. 
Sagüés, Nestor. Pedro (2007). "Manual de derecho constitucional", Buenos Aires, Ed. Astrea.

Zaffaroni, Eugenio Raúl (2002). "Contra la crisis, más democracia", Diario Clarín, Buenos Aires.

Zaffaroni, Eugenio Raúl (2003). Prologo en Ferreyra, Raúl Gustavo. (2003). "La constitución vulnerable. Crisis argentina y tensión interpretativa”. Ed. Ed.Hammurabi, p. 10.

\section{Jurisprudencia}

CSJN (1957). "Perón, Juan Domingo”, 21/07/1957, Fallos 238:76.

CSJN (1990). "Peralta, Luis Arcenio y otro c/ Estado Nacional (Mrio. de Economía BCRA.) s/ amparo”, 27/12/1990, Fallos 313:1513.

CSJN (2002). "Tobar, Leónidas c/ Estado Nacional -Ministerio de Defensa- Contaduría General del Ejército - Ley $25.453 \mathrm{~s} / \mathrm{am}-$ paro ley 16.986", 22/08/2002, Fallos: 325:2059, cons. 8.

CSJN (2009). "Bankboston N.A. c/ Jane Javier Esteban s/ejecución hipotecaria", 10/11/2009, Fallos 332:2468. 